\title{
La Producción de Lechuga en Sistemas Hidropónicos a Pequeña Escala ${ }^{1}$
}

\author{
Germán V. Sandoya, Jonael Bosques, y E. Vanessa Vassilaros²
}

\section{Introducción}

La lechuga es uno de los vegetales de mayor consumo en los Estados Unidos (USDA NASS 2020). Normalmente la lechuga se consume en ensaladas y se utiliza como guarnición con otros alimentos. En el oeste de los Estados Unidos, este cultivo se produce todo el año y se distribuye a los mercados que no poseen producción local. Debido a que la lechuga viaja largas distancias desde las fincas productoras hasta el lugar de consumo, el transporte incrementa el impacto ambiental asociado con la huella de carbono significativamente y afecta la calidad y frescura de la lechuga. Por lo tanto, se debe incrementar la producción local de la lechuga. En Florida, durante los meses de noviembre hasta abril, los agricultores plantan y proveen lechugas frescas a los consumidores locales. Las tendencias actuales que se enfocan en la huella de carbón y la sustentabilidad de los productos agrícolas hacen que la lechuga producida localmente en Florida tenga una ventaja en cuanto a mercadeo debido a su frescura y calidad, la cual hace que este cultivo sea uno de los más lucrativo para agricultores locales en comparación con la importación de otros estados como California y Arizona.

La lechuga producida en Ambientes Controlados (ACs), como en sistemas hidropónicos (Figura 1), acuapónicos, y en sistemas de producción vertical, pueden proveer productos frescos deseables para los consumidores de
Florida (Tyson, Hochmuth, y Cantliffe 2010). En Florida, hay cuatro áreas metropolitanas en las cuales se concentra la mayor parte de la población del estado, estas áreas se encuentran en los condados de Miami-Dade, Broward, Palm Beach en el sur, Orange y Osceola en el centro, Pinellas, Hillsborough, Manatee en la bahía de Tampa y la zona cercana a la ciudad Jacksonville en el norte. Desde el 2010 hasta el 2019, la población en Florida incrementó en un $14.2 \%$ convirtiéndose en el tercer estado más poblado de los Estados Unidos (US Census 2019). Por tanto, la producción de vegetales en ACs podría ser una alternativa sostenible y rentable para satisfacer la demanda del consumidor local con respecto a lechuga fresca, especialmente cuando ésta es producida cerca de las grandes metrópolis densamente pobladas.

\section{Producción de Lechuga en Ambientes Controlados}

En la producción de vegetales como la lechuga en ACs, se utiliza y manipula los factores ambientales y se crea la opción de producir cultivos sin la utilización de suelos. La técnica que se conoce como hidroponía es un método de cultivo antiguo que data de civilizaciones que sobrevivían plantando cultivos sin suelos. Históricamente, la producción hidropónica data del tiempo de los aztecas, incas, egipcios, babilonios y chinos.

1. Este documento es HS1422s, uno de una serie del Departamento de Horticultura, UF/IFAS Extensión. Fecha original de la publicación febrero 2021. Visite el sitio web de EDIS: https://edis.ifas.ufl.edu para la versión de esta publicación más actualizada.

2. Germán V. Sandoya, profesor asistente, Horticultural Sciences Department, UF/IFAS Everglades Research and Education Center; Jonael Bosques, director de Extensión y agente de agricultura, UF/IFAS Extension Hardee County, y E. Vanessa Vassilaros, agente de Extensión en agricultura/ horticultura comercial y ornamentales, UF/IFAS Extension Miami-Dade County; UF/IFAS Extension, Gainesville, FL 32611.

The Institute of Food and Agricultural Sciences (IFAS) is an Equal Opportunity Institution authorized to provide research, educational information and other services

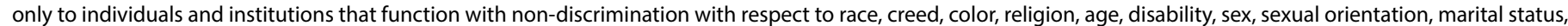

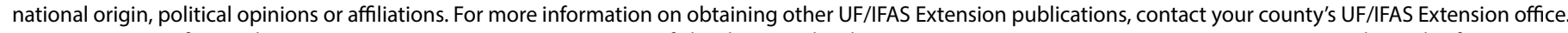
U.S. Department of Agriculture, UF/IFAS Extension Service, University of Florida, IFAS, Florida A \& M University Cooperative Extension Program, and Boards of County Commissioners Cooperating. Andra Johnson, dean for UF/IFAS Extension. 


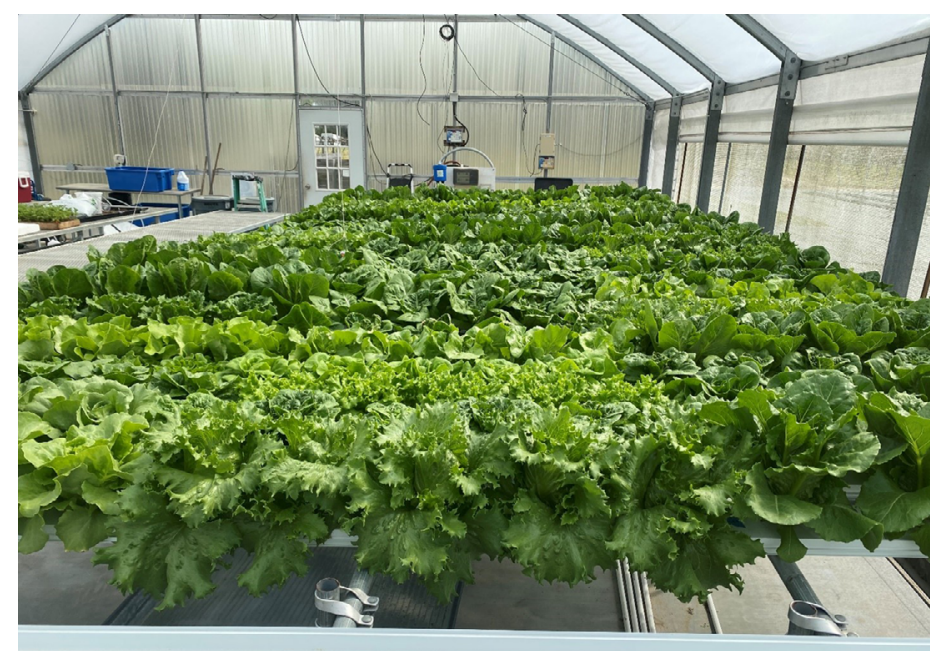

Figura 1. Lechuga cultivada en un sistema hidropónico semi-comercial (Tipo Nutrient Film Technique-NFT) en North Florida Research and Education Center, Live Oak, FL., Condado de Suwannee. Credits: Germán Sandoya, UF/IFAS

Los sistemas contemporáneos de cultivo sin la utilización de suelos se conocen como "Hidropónicos" (Griego: "hydro"-significando agua; "Ponos"—-significando trabajo). Se conoce por extensa investigación que el suelo no es esencial para el crecimiento de las plantas. Normalmente las plantas que se siembran en el suelo lo utilizan como medio de anclaje y para extraer los minerales esenciales para completar su crecimiento vertical en dirección a la fuente de luz.

La proporción de los nutrientes minerales encontrados en el suelo se libera por la descomposición bacteriana y de otros organismos (lombrices, hongos, etc.) presentes en el sustrato. Estos nutrientes se disuelven lentamente en el suelo y forman una solución acuosa la cual se absorbe por las raíces. Todas las plantas tienen las mismas necesidades en cuanto a los nutrientes esenciales para su crecimiento sin importar si crecen en tierra o en otro sustrato.

Hoy en día los aficionados a la jardinería pueden producir sus propias lechugas para consumo casero en espacios pequeños o limitados debido a la capacidad de suplementar con luz artificial en los ACs. La producción de lechuga en sistemas hidropónicos caseros es generalmente una inversión rentable (Figura 2); pero se deben considerar varios aspectos antes de comenzar a producir en los mismos. Estos aspectos son: el tipo de sistema, el acceso a luz natural apropiada, selección apropiada de variedades, entre otros factores importantes que se explican en este documento. Esta publicación tiene como intención despertar el interés en producir lechuga en sistemas hidropónicos pequeños. También tiene como intención ayudar a los interesados en seleccionar un sistema apropiado para su hogar.

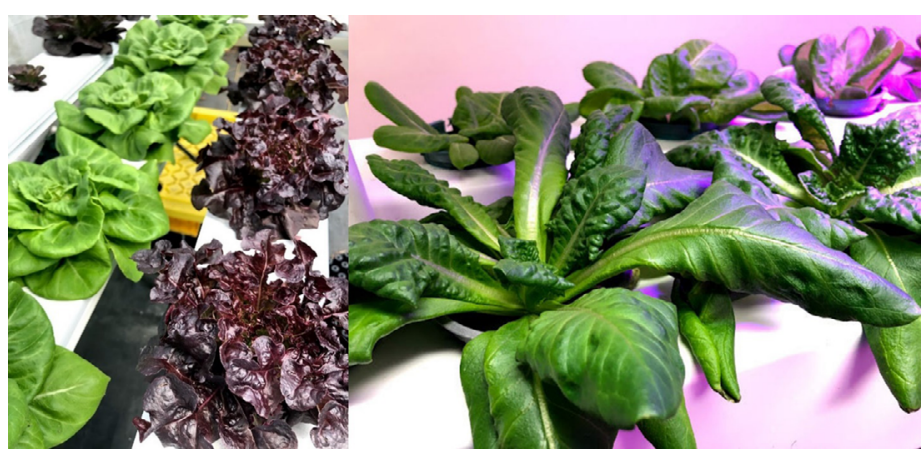

Figura 2. Plantas de Lechuga cultivada en dos sistemas hidropónicos pre-fabricados tipo "Nutrient Film Technique (NFT)" a pequeña escala. Credits: Jonael Bosques, UF/IFAS

\section{Consideraciones Generales}

- Escoja el sistema hidropónico adecuado (en este documento se describen los sistemas disponibles).

- Decida por un cultivar de lechuga adaptado a condiciones de días cortos y clima cálido.

- Familiarícese con las plantas a sembrar en su sistema. Para esto, utilice un registro de producción detallado y anote los cambios que haga durante la temporada de crecimiento. Esta información puede ayudarle a prevenir problemas en el futuro.

- Haga observaciones regulares para prevenir la invasión por plagas y enfermedades las cuales potencialmente pueden afectar el crecimiento de sus plantas.

- Contacte a su agente local de Extensión de UF/IFAS para recomendaciones adicionales.

\section{Consideraciones Específicas}

\section{Sustratos para las plantas (Medios de crecimiento).}

Escoja el sustrato adecuado para la producción de lechugas en su sistema hidropónico bajo AC. Existen muchos tipos de sustrato en el mercado incluyendo: vermiculita, corteza de pino compostada, agregados expandidos de arcilla (Light weight expanded clay agregate o LECA por sus siglas en inglés), roca de lana, perlita y fibra de coco. Otros sustratos que se pueden utilizar incluyen roca de río (Figura 3 ).

1. Vermiculita-es un material que resulta del calentamiento del silicio. Al calentarse este mineral se forman capas finas entre las cuales el aire y soluciones acuosas se almacenan para interactuar con raíces de las plantas. Este medio es una excelente opción para el desarrollo de raíces y el intercambio de nutrientes. La vermiculita se puede encontrar en diferentes grados dependiendo del tamaño de partícula, desde "fino" hasta "extra grueso".

2. Corteza de pino compostada-Este material está disponible en áreas en las cuales existe una industria 
maderera activa. La corteza compostada de árboles de pino provee un medio para las plantas que ayuda con estabilizar el $\mathrm{pH}$ de alto a bajo en la solución nutritiva. Otra consideración que debe mencionarse es que el proceso de compostaje tiene que completarse antes de usarse y este tiene la capacidad de secuestrar (o fijar) el nitrógeno $(\mathrm{N})$ de la solución, que resulta en mayor inversión de $\mathrm{N}$ comparado con otros medios.

3. Agregados expandidos de arcilla (LECA) - las "esferas de arcilla", como la perlita son el producto de calentar arcillas a $2192^{\circ} \mathrm{F}$ en un horno rotativo (la rotación determina la forma de las esferas). Los gases que quedan atrapados en la arcilla se expanden y producen un patrón similar a un panal de abejas microscópicos en cada pieza.

4. Lana de roca-Se consigue en cubos prefabricados con agujeros para colocar la semilla. La lana de roca se fabrica al forzar vapor húmedo a través de la roca derretida. Como resultado las fibras minerales quedan entretejidas y compactadas en capas. Este sustrato tiene la capacidad de aguantar líquidos por capilaridad y mantener espacios de aire. La mayor parte de estos sustratos comerciales requieren humedecer el medio en soluciones amortiguadoras de acidez antes de utilizarse para neutralizar la alcalinidad del medio.

5. Perlita-Este sustrato se deriva de rocas volcánicas altamente porosas. Estas rocas están sujetas a altas temperaturas lo que produce una expansión del medio. La perlita se utiliza comúnmente como mezclas para atrapar aire y humedad en potes o macetas con plantas ornamentales.

6. Fibra de coco-Este sustrato se deriva de la industria del coco. La fibra de coco se utiliza frecuentemente en mezclas para plantas ornamentales. La cáscara del coco se muele y luego se compacta con el propósito de almacenarse en paquetes o bloques y pastillas compactas. Este medio de crecimiento provee espacios de aire y almacenamiento de agua y nutrientes, así como también porosidad para el desarrollo radicular. Como medio orgánico similar a la corteza de pino compostada, este medio es propenso al secuestro de $\mathrm{N}$, pero a su vez se puede reutilizar o compostar totalmente después de su uso en la producción de lechugas caseras.

7. Roca de río-Este medio es extremadamente pesado. La roca o grava de río provee superficies que promueven la capilaridad del agua, pero posee una capacidad limitada para almacenar la misma.

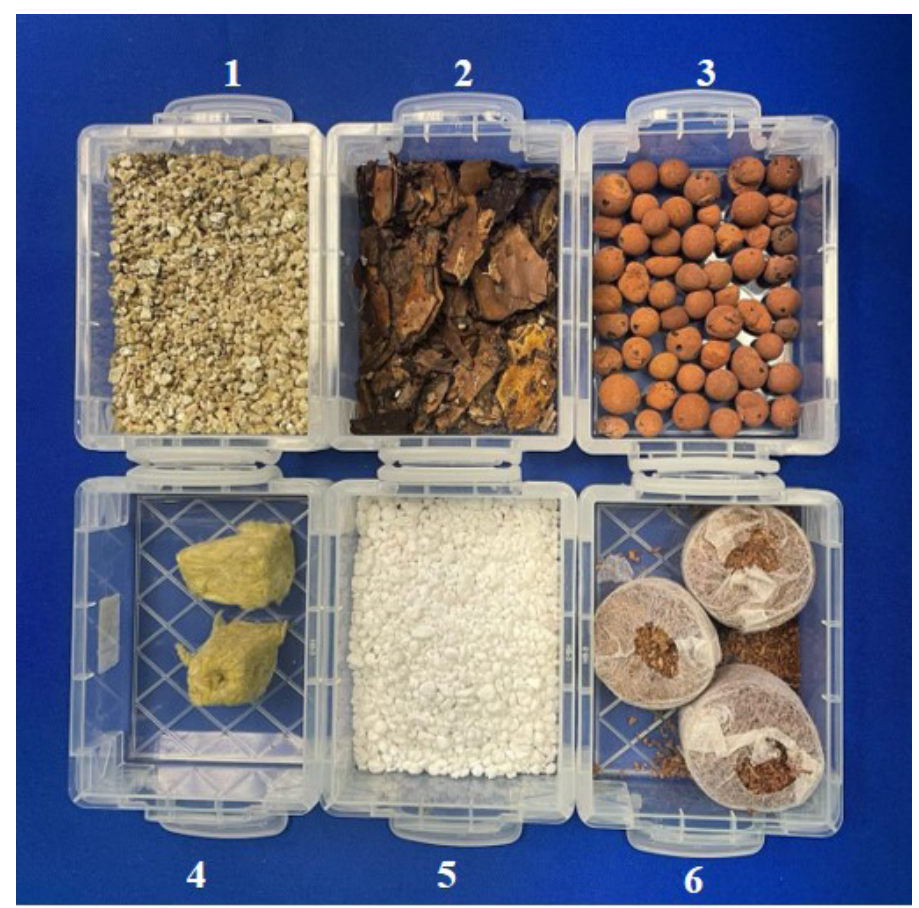

Figura 3. Ejemplos de sustratos ideales para sistemas hidropónicos a pequeña escala. Vermiculita (1), Corteza de pino compostada (2), LECA (3), Lana de roca (4), Perlita (5), y Fibra de Coco (6).

Credits: Jonael Bosques, UF/IFAS

Nutrición de plantas. Como en sistemas en los cuales se siembra en el suelo, la lechuga necesita la nutrición apropiada para producir satisfactoriamente las demandas de nutrición y de mercado. Se pueden encontrar muchas formulaciones con las cantidades adecuadas de nitrógeno $(\mathrm{N})$, fósforo $(\mathrm{P})$ y potasio $(\mathrm{K})$, o también conocidos por las siglas N-P-K (macronutrientes), que a su vez proveen las cantidades requeridas de micronutrientes. Las formulaciones completas para uso en sistemas hidropónicos deben tener las cantidades adecuadas de macronutrientes, nutrientes secundarios y micronutrientes. Se recomienda familiarizarse con las diferentes formulaciones disponibles en el mercado y seleccionar la que mejor se ajuste a las exigencias de la variedad y las condiciones ambientales en las que se desarrolle el cultivo. Esta evaluación se basa en los rendimientos y el costo de producción.

Otro aspecto importante a considerar en relación a la solución nutritiva es la Conductividad Eléctrica (CE, o electrical conductivity, EC, por sus siglas en inglés). Esta se define como la cantidad de nutrientes disueltos den la solución. Se requiere monitorear con regularidad y ajustar de ser necesario la conductividad eléctrica de la solución hidropónica, lo cual se define a la cantidad de sales disueltas en el agua.

- Mida la CE durante la formulación de la solución nutritiva. 
- Mantenga una CE adecuada para evitar deficiencias nutricionales o daños por quemadura a las raíces.

- El rango de CE ideal para lechugas es de 1.4 a $1.8 \mathrm{mS} / \mathrm{cm}$ y un pH de 6.0-7.0.

- Para más información acerca de CE, consulte el siguiente enlace en inglés: https://extension.okstate.edu/fact-sheets/ electrical-conductivity-and-ph-guide-for-hydroponics. html

Iluminación artificial o suplementaria. En ACs puede ser necesario suplementar con luz artificial el cultivo para obtener un crecimiento óptimo en la lechuga, especialmente cuando se produce en interiores o en sombra parcial (Figura 4). Los cultivares de lechuga para las condiciones de Florida están adaptados para recibir 10 a 11 horas de luz por día. Los cultivares desarrollados para latitudes más al norte necesitarán mayor cantidad de horas luz especialmente en el invierno.

- Más información relacionada al espectro de luz y las diferentes fuentes se pueden consultar en inglés https:// cea.cals.cornell.edu/lighting/.

- En ACs cuando se utilizan sistemas hidropónicos pequeños, puede ser necesario que la cantidad de horas o la distancia entre la fuente de luz y la planta se ajuste dependiendo de la etapa de crecimiento del cultivo. Hay varios aspectos a considerarse en este caso:

- La luz demasiado cerca de las plántulas puede resultar en quemaduras a la hoja

- La luz demasiado distante de las plántulas puede resultar en elongación de los tallos y plantas débiles.

- Demasiadas horas luz pueden resultar en estancamiento de crecimiento y deformidad en las hojas.

Selección de sistema hidropónicos. Escoja su sistema hidropónico tomando en consideración su presupuesto, el espacio disponible y las características del cultivo a plantar.

1. Presupuesto-muchos sistemas prefabricados están disponibles en el mercado (Figura 3). Sin embargo, usted puede construir su propio sistema específicamente diseñado para satisfacer sus necesidades.

2. Espacio-existen sistemas verticales diseñados para crecer plantas en diferentes niveles. Si el espacio no es una limitación, puede considerar otros sistemas de tipo horizontal. Ambos tipos tienen sus ventajas y desventajas.

3. Cultivo-cultivos de ciclo corto (50-60 días) como lo es la lechuga pueden producirse en una gran variedad de sistemas. Sin embargo, cultivos de ciclo largo o perennes (>60 días) deben sembrarse en sistemas los cuales provean más espacio para el desarrollo de raíces, ramas y tallos. Los sistemas de NFT (Nutrient Film Technique-por sus siglas en inglés) y cama flotante son sistemas diseñados para ciclos corto de producción. Los agricultores y jardineros que deseen crecer sus cultivos en estos sistemas deben considerar el tipo de planta y combinarlo con el diseño hidropónico adecuado.

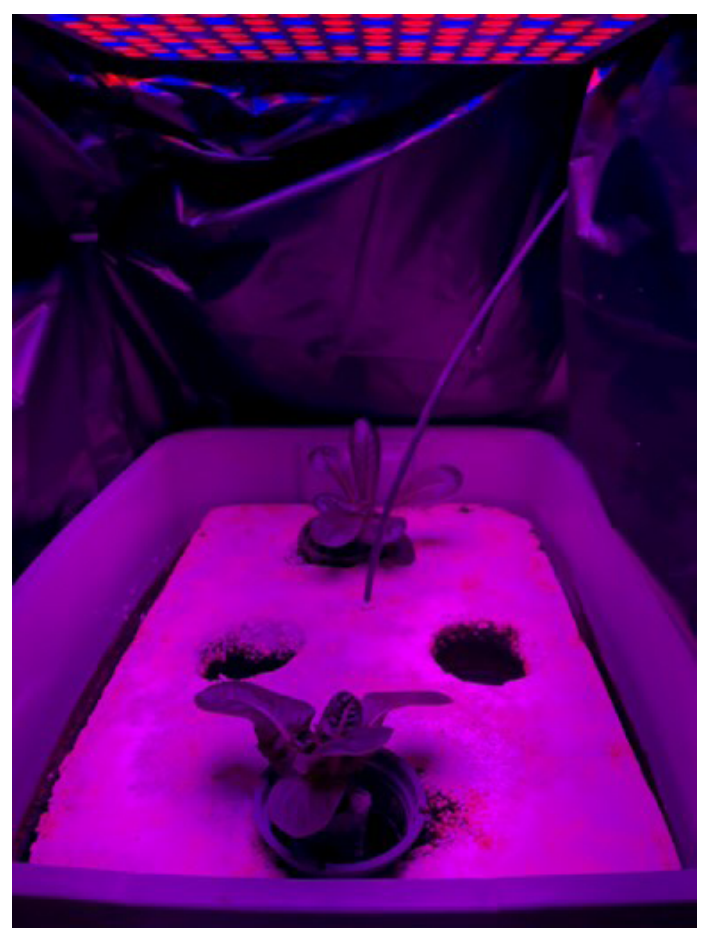

Figura 4. Plantas de Lechuga cultivada bajo luces LED. Credits: Jonael Bosques, UF/IFAS

\section{Sistemas Hidropónicos para Espacios Limitados Sistemas de riego por goteo}

El uso de líneas de riego añade flexibilidad al diseñar un sistema hidropónico casero. Con la adición de un reloj temporizador al sistema se puede regar las plantas con precisión para cumplir con los requerimientos hídricos y nutricionales. Algunos sistemas de riego por goteo pueden diseñarse para recircular el agua de riego, o solo para regar estratégicamente sin recircular la solución nutritiva (sistemas abiertos).

Sistemas abiertos. En estos sistemas hidropónicos la solución con fertilizantes se distribuye a través de mangueras de riego por goteo y el efluente (solución nutritiva restante luego de atravesar el área radicular de las plantas) no se reutiliza. Este sistema consiste usualmente de una tubería primaria de riego que se subdivide en líneas secundarias, dependiendo del diseño. En la mayoría de los casos las tuberías de riego por goteo depositan un volumen 
predeterminado en cada contenedor, cerca de la base de la planta (Figura 5). A este sistema se le puede adaptar un canal de recolección para atrapar el efluente y reutilizarlo para regar otras plantas fuera del sistema.

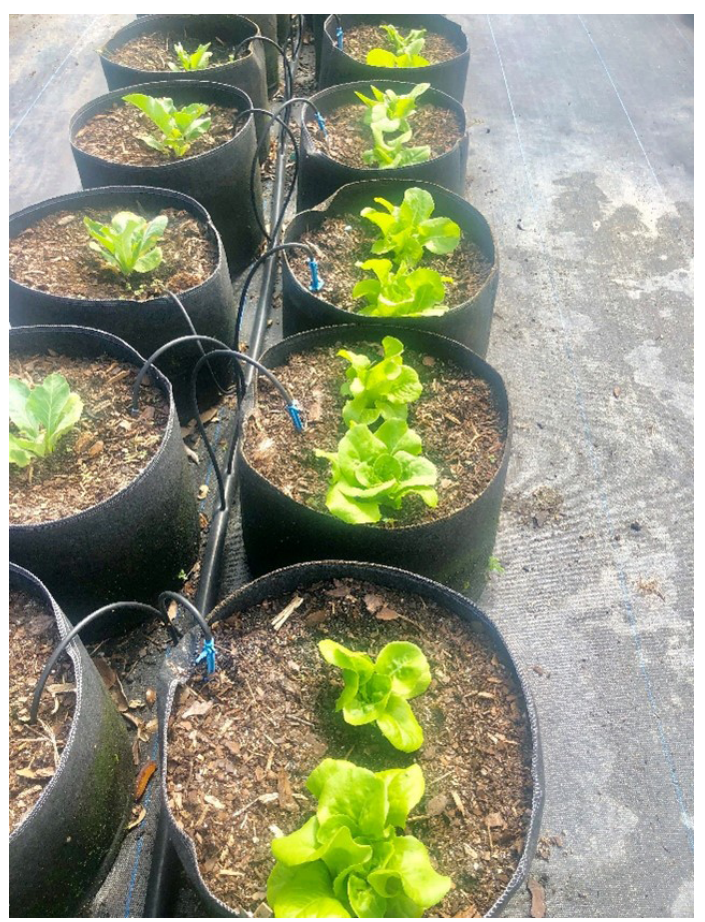

Figura 5. Sistema de riego abierto para cultivar lechugas. Credits: Germán Sandoya, UF/IFAS

Recirculante. Este sistema incluye una reserva para la solución nutritiva y una bomba de riego la cual recicla el líquido de manera constante. Se necesita monitorear la solución nutritiva para asegurarse que el $\mathrm{pH}$, el oxígeno disuelto y la $\mathrm{CE}$ se encuentren en óptimas condiciones para permitir el desarrollo de la planta en cada etapa de crecimiento (Figura 6).

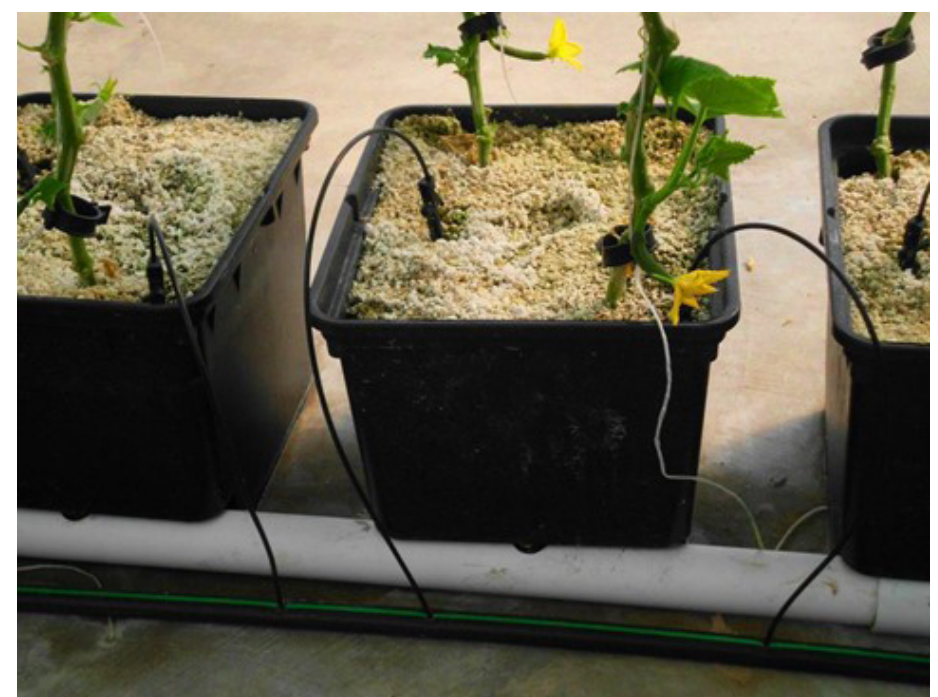

Figura 6. Sistema recirculante "Bato Bucket" (en idioma inglés) el cual se puede adaptar para producción de lechugas.

Credits: Jonael Bosques, UF/IFAS
Note que las piezas y tuberías del sistema de riego por goteo pueden bloquearse cuando el agua es alcalina. La inspección constante de estos sistemas debe ser una práctica rutinaria para verificar la distribución uniforme de solución de riego y asegurar el crecimiento adecuado de cada planta en el sistema. Verifique el contenido de calcio en el agua potable. Hay que tener en cuenta que el calcio que se produce naturalmente en la solución no sustituye el que se le añadirá a la solución nutritiva para suplir las necesidades metabólicas de la lechuga.

\section{Camas de mezcla de sustratos}

Este sistema es ideal para cultivos de ciclo corto como la lechuga. Las camas pueden diseñarse con desniveles que sean cómodos para la accesibilidad y mejor postura del jardinero. Las camas se pueden adaptar para permitir la captura del efluente y la recirculación. Las plántulas de lechuga deben sembrarse en líneas bajo estructuras protegidas (invernaderos o estructuras de crecimiento con lados abiertos los cuales protegen a las plantas de eventos climatológicos como exceso de lluvia o heladas). Por la peculiaridad de que el medio de crecimiento es una mezcla entre compost y otros ingredientes antes descritos, el riego puede ser por goteo y el fertilizante sólido puede ser incorporado en el sustrato (Figura 7).

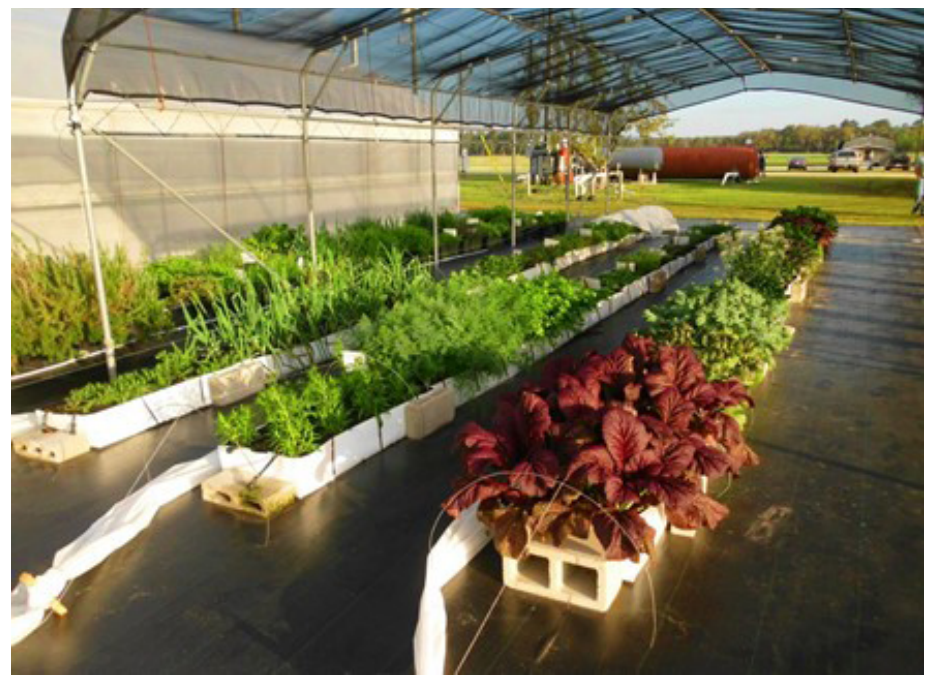

Figura 7. Camas de mezcla de sustratos.

Credits: Jonael Bosques, UF/IFAS

\section{Sistema de Lámina de Nutrientes (Nutrient Film Technique o NFT por sus siglas en inglés)}

El NFT es una técnica hidropónica en la cual tradicionalmente se usa muy poco sustrato. La solución nutritiva se hace recircular y dispersar a través de canaletas o tubos de PVC que luego se drena y transporta a un dispositivo de reservas de líquido. Los jardineros aficionados pueden 
comprar un sistema NFT prefabricado (Figura 8) o pueden construir su propio sistema. Aparte de los materiales antes mencionados, los operadores necesitarán relojes temporizadores, y en algunos casos, suplementación de luz con lámparas. El NFT puede ser modificado para la producción paralela de peces (acuaponía-la cultura de peces y plantas en el mismo sistema).

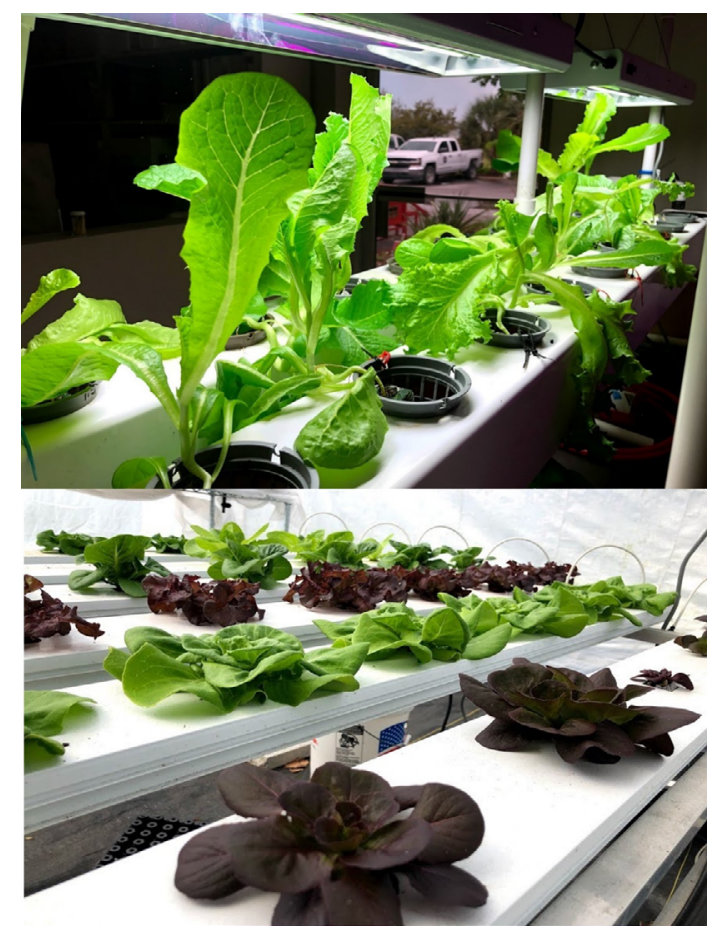

Figura 8. Dos sistemas NFT para cultivar lechugas en espacios pequeños.

Credits: Jonael Bosques, UF/IFAS

\section{Sistema Flotante o de Balsa}

Este sistema utiliza planchas de Styrofoam (o espuma de poliestireno) con agujeros para colocar contenedores para las plantas. La solución nutritiva se reserva en un contenedor plástico en la cual descansa la plancha antes mencionada. Este sistema es ideal para cultivos de ciclo corto como lechuga (Figura 9).

Para más información acerca de cómo construir un sistema flotante consulte la publicación EDIS HS943 o HS1210: https://edis.ifas.ufl.edu/publication/hs1210 (Bosques, Tyson y Hochmuth, 2003).

Partes esenciales del sistema:

1. Contenedor (puede ser plástico o cualquier material que se adapte a condiciones específicas)

2. Cubierta de material impermeable (3 o $6 \mathrm{ml}$ )

3. Plancha de Styrofoam (2 pulgadas de grosor)
4. Cubierta de tela para el suelo

5. Aireador

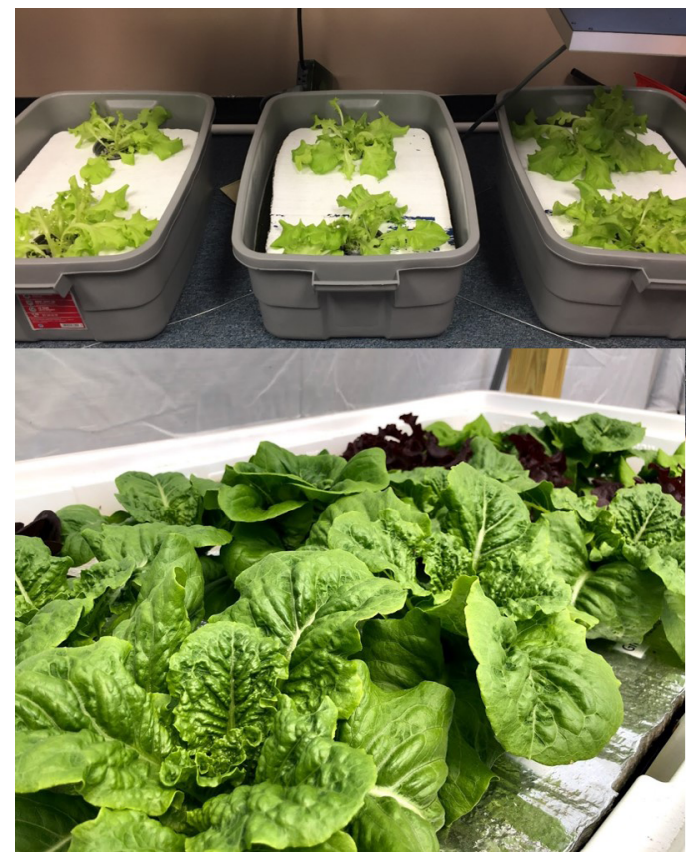

Figura 9. Dos sistemas hidropónicos flotantes para producir lechuga. Credits: Jonael Bosques, UF/IFAS

\section{Sistema Vertical}

Este sistema está diseñado para producir cultivos en columnas verticales que reciben riego desde la parte superior $\mathrm{o}$ individualmente en cada nivel de crecimiento. El sistema incluye bolsas que se colocan en un arreglo vertical o en contenedores que se colocan alternadamente uno encima de otro donde se siembran las plántulas (Figura 7).

Hay que tener en cuenta que la falta de una iluminación uniforme es una desventaja en este tipo de sistemas, ya que la sombra de plantas en la parte superior puede afectar el crecimiento de las plantas que se siembran en niveles bajos. Otro problema asociado a este sistema es la falta de flujo de aire entre plantas. Disipar el exceso de humedad es importante para mantener las plántulas de lechuga libre de enfermedades causadas por hongos y bacterias.

Partes esenciales del sistema:

\section{Contenedores}

2. Reserva para la solución nutritiva

3. Sistema de riego

4. Medio de crecimiento

5. Reloj temporizador (opcional) 


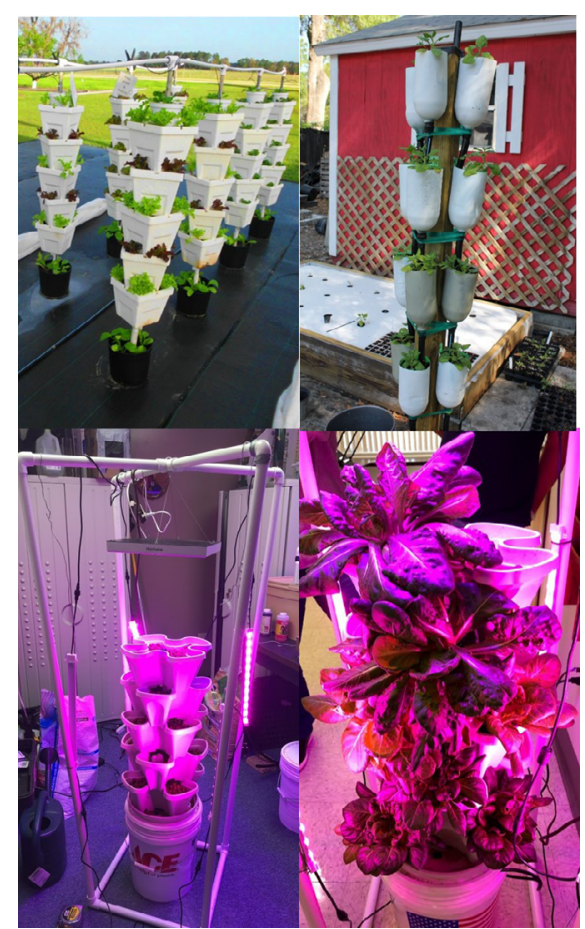

Figura 10. Torre vertical para cultivar lechugas en ACs. Credits: Jonael Bosques, UF/IFAS

\section{Consideraciones Adicionales}

- Solución nutritiva-se debe monitorear de manera constantemente. La temperatura en la solución debe estar entre los $65-85^{\circ} \mathrm{F}$. Debe tener buena oxigenación (oxígeno disuelto $=5 \mathrm{mg} / \mathrm{L}$ ), y la EC debe estar entre $1.2 \mathrm{y}$ $1.8 \mathrm{~ms}$ (560-840 ppm). Los jardineros aficionados deben adquirir medidores de $\mathrm{pH}$, Conductividad Eléctrica (CE), temperatura y de oxígeno disuelto. Existen muchos modelos con funciones múltiples de bajo coste.

- Riego: tiempo y cantidad-el exceso de agua puede causar problemas de pudrición de la raíz en la mayoría de los sistemas. La irrigación constante no es necesaria si el sistema radicular tiene acceso a suficiente humedad para remplazar su ritmo de transpiración natural. Un reloj temporizador es necesario para controlar la cantidad de agua a la cual se expone la planta en combinación con un buen diseño de drenaje; su uso es sumamente importante para todos los sistemas antes mencionados.

- En teoría, la lechuga producida en ACs debería tener menor incidencia de plagas y enfermedades. Sin embargo, el monitoreo sigue siendo necesario para prevenir estos organismos que pueden afectar la calidad de la lechuga. Una inspección regular del cultivo es una buena inversión. Plantar semilla certificada libre de patógenos y plagas es una de las mejores recomendaciones para evitar la introducción de plagas y enfermedades. Si se detecta la presencia de plagas, siga los pasos para el manejo integrado de plagas/enfermedades, el cual incluye inspecciones, monitoreo y manejo a la escala que sea aplicable. Para más información acerca de cómo controlar estos enemigos del cultivo de lechuga, consulte con su agente de Extensión. Existen varias publicaciones en el servicio de Extensión de la Universidad Estatal de la Florida o en UF/IFAS EDIS (o Ask IFAS) las cuales ofrecen información relacionada al control y prevención de plagas y enfermedades: https://edis.ifas.ufl.edu/cv248; https://edis.ifas.ufl.edu/cv274 (Rich et al. 1990; Webb and Hochmuth 1990).

\section{Recursos Adicionales}

- La información relacionada a fincas pequeñas puede ser útil para implementar en los jardines y huertos caseros. Mas información acerca de fincas pequeñas y sistemas de producción de alimentos se encuentra disponible en el sitio web de fincas pequeñas de la Universidad de la Florida: https://smallfarm.ifas.ufl.edu/.

- El manual de producción hidropónica de lechugas contiene más información en el cultivo de esta bajo los sistemas mencionados: https://cpb-us-e1.wpmucdn.com/ blogs.cornell.edu/dist/8/8824/files/2019/06/Cornell-CEALettuce-Handbook-.pdf. Se debe tener en consideración que mucha de la información es aplicable a escala comercial y ACs tipo invernadero, los jardineros aficionados pueden extrapolar y aplicar estas recomendaciones a espacios limitados y sistemas de producción pequeños.

- Para información adicional contacte a su agente de Extensión de UF/IFAS más cercano a su lugar de residencia.

- Esta publicación se encuentra en idioma inglés en este enlace: https://edis.ifas.ufl.edu/publication/HS1422.

\section{Referencias}

Rich, J. R., S. E. Webb, M. L. Paret, and T. M. Momol. 1990. "Considerations for Managing Greenhouse PestsFlorida Greenhouse Vegetable Production Handbook, Vol 3." EDIS 2013 (5). https://edis.ifas.ufl.edu/cv248

Sweat, M., R. Tyson, and R. Hochmuth. 2003. "Building a Floating Hydroponic Garden.” EDIS 2004 (1). https://doi. org/10.32473/edis-hs184-2003

Tyson, R., R. Hochmuth, and D. Cantliffe. 2010. "Hydroponic Vegetable Production in Florida." EDIS 2010 (1). https://journals.flvc.org/edis/article/view/118314

USDA National Agricultural Statistics Service. 2020. "State Agricultural Overview.” Accessed 10 March 2021. https:// quickstats.nass.usda.gov/ 
Webb, S. E., and R. Hochmuth. 1990. "Vegetable Insect Identification and Management-Florida Greenhouse Vegetable Production Handbook, Vol 3." EDIS 2010

(4). https://journals.flvc.org/edis/article/view/118660 